\title{
latrogenic illness in the paediatric intensive care unit at Gharian teaching hospital, Libya
}

A.M. Ismail and S.A. Shedeed ${ }^{2}$

$$
\text { ألحدي إسماعيل، سعاد شديد المنشأ في وحدة الرعاية المركّزة للأطفال في المستشفى التعليمي في غريان، ليبيا }
$$

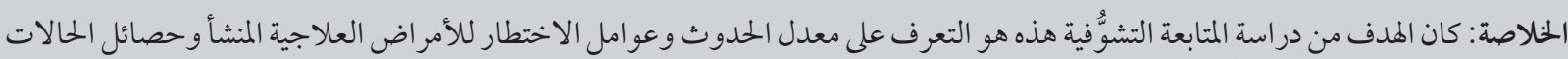

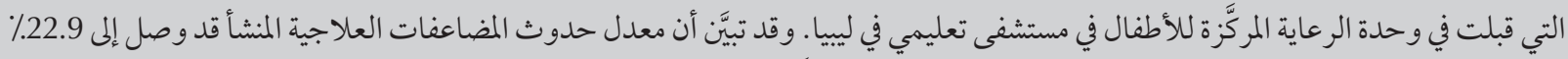

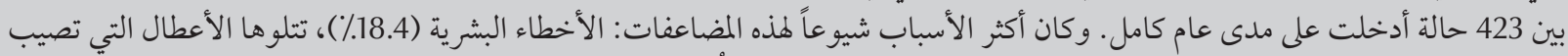

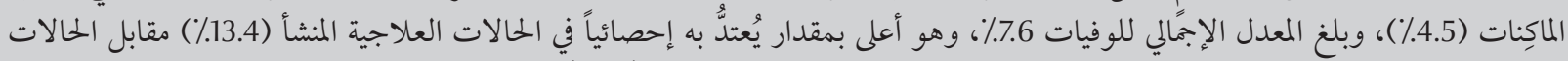



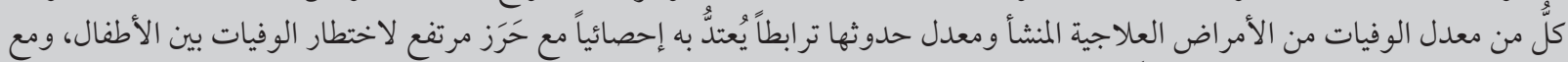



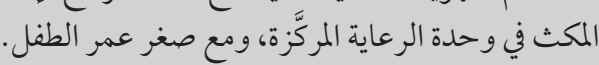

ABSTRACT The aim of this prospective follow-up study was to determine the incidence and risk factors of iatrogenic illness and the outcome among cases admitted to the paediatric intensive care unit in a teaching hospital in Libya. The incidence of iatrogenic complications was $22.9 \%$ among 423 cases admitted over a 1-year period. Human error (18.4\%) followed by machine defects $(4.5 \%)$ were the most common causes of complications. The overall mortality rate was $7.6 \%$ and was significantly higher in iatrogenic cases than others (13.4\% versus $5.8 \%$ ). Paediatric risk of mortality (PRISM) score was a good predictor of risk of iatrogenic illness. Both mortality and occurrence of iatrogenic illness were significantly associated with: higher PRISM score, use of mechanical ventilation, higher bed occupancy rate in the unit, presence of respiratory and neurological diseases, prolonged duration of stay in the intensive care unit and younger age of the child.

\section{Maladies iatrogènes en unité de soins intensifs pédiatriques à l'hôpital universitaire de Gharian en Libye}

RÉSUMÉ La présente étude prospective de suivi visait à déterminer l'incidence et les facteurs de risque des maladies iatrogènes ainsi que leur évolution chez des patients admis en unité de soins intensifs pédiatriques d'un hôpital universitaire en Libye. L'incidence des complications iatrogènes était de 22,9 \% sur 423 patients admis au cours d'une période d'un an. La cause de complications la plus fréquente était l'erreur humaine $(18,4 \%)$ suivie par les dysfonctionnements techniques $(4,5 \%)$. Le taux de mortalité globale était de $7,6 \%$, mais s'avérait nettement supérieur pour les cas iatrogènes (13,4\% par rapport à 5,8 \%). Le score PRISM (Paediatric risk of mortality score) était un bon indicateur prédictif de maladie iatrogène. La mortalité tout comme la survenue d'une maladie iatrogène étaient fortement associées aux éléments suivants : un score PRISM élevé, le recours à la respiration artificielle, un taux d'occupation des lits important dans l'unité, la présence de maladies respiratoires et neurologiques, un séjour prolongé dans l'unité de soins intensifs et l'âge particulièrement jeune de l'enfant.

${ }^{'}$ Department of Community, Environmental and Occupational Medicine, Faculty of Medicine, University of Benha, Benha, Egypt. ${ }^{2}$ Department of Paediatrics, Faculty of Medicine, University of Zagazig, Zagazig, Egypt (correspondence to S.A. Shedeed: soadshedeed@gmail.com). Received: 15/02/10; accepted: 22/06/10 


\section{Introduction:}

The paediatric intensive care unit (PICU) has evolved as a unique setting for the care of children with unstable or life-threatening illness. The primary goal of intensive care is to prevent mortality in patients with reversible critical illness [1]. Despite efforts to provide the best care, complications may continue to occur in the critically ill patient, either because of the natural course of the disease or after a procedure or institution of a new therapy [2].

Iatrogenic illness is defined as an unexpected adverse condition that occurs as a result of medical care and is independent of the patient's underlying disease. It is an important determinant of the need for paediatric intensive care [3]. Iatrogenic illness has been classified as either due to complications of drugs or complications of a medical or surgical act [4]. The occurrence of nosocomial infection as an iatrogenic complication has been demonstrated to increase the risk of death in critically ill patients and the incidence of nosocomial infection remains high especially in patients receiving critical care. Poor staff hygiene is considered to be leading source of infections acquired during hospitalization [5]. Monitoring of critically ill patients to assess their current status and anticipate problems is essential to paediatric critical care and the assessment of PICU outcome has been done to evaluate the effectiveness and efficiency of such care [1]. The aims of the current study were to determine the incidence and risk factors for iatrogenic illness, together with the outcome among cases admitted to the PICU of a teaching hospital in Libya in an attempt to prevent or minimize such illness.

\section{Methods}

\section{Sample and setting}

This was a prospective follow-up study of all cases admitted to the PICU of
Gharian teaching hospital during the period December 2007 to December 2008. The total number of beds in the PICU was 5. The staffing of the unit over 24 hours was divided into 2 shifts; each shift routinely included 2 doctors, 2 nurses and 1 ancillary worker. In this study we excluded cases with low Glasgow coma scale (below 3 ) and patients who died within the first hour of admission.

\section{Data collection}

Data were collected from all patients regarding age, sex and primary diagnosis, after which patients were classified into medical emergency, surgical emergency or elective admission status. Severity of the illness was assessed at the end of admission day using the paediatric risk of mortality score (PRISM score) according to Gale [6]. Laboratory investigations were carried out for diagnostic purposes (serum calcium, sodium, potassium, creatinine, blood urea, prothrombin time, partial thromboplastin time, serum bilirubin and aspartate and alanine aminotransferases) and are not reported here. The bed occupancy rate in the unit at the time each case was admitted was determined by dividing the number of cases including this case by the total number of beds in the PICU (i.e. 5 beds) according to Thierry et al. [7].

Iatrogenic illness was assessed as present or absent according to the criteria of Joseph et al.[3]. If present, we determined whether it happened in the PICU and the type, i.e. whether it could be attributed to human error (adverse drug events, vascular catheter complication, nosocomial infection, cutaneous injury, bedsore, accidental extubation, laryngeal dyspnoea) or to a machine/equipment error (ventilator or other equipment, monitor malfunction) according to Joseph et al. [3]. The severity of each iatrogenic complication was classified as: minor (resolved spontaneously), moderate (required only routine therapy) or major (fatal or life-threatening if a specific intensive care therapy was required to treat the iatrogenic complication e.g. artificial ventilation) [8]. The duration of stay inside the PICU and outcome of the patients (alive or dead) were also determined.

\section{Statistical analysis}

The collected data in this study were statistically presented and analysed using descriptive statistics, chi-squared test, relative risk, confidence interval and correlation. We used Spearman correlation test for ordinal variables and numerical skewed variables and Pearson correlation test for interdependent numerical variables. Significance was accepted at a level of $\mathrm{P}<0.05$. Analyses were performed using the statistical software package SPSS, version 7.0 for Windows.

\section{Results}

\section{Background characteristics}

This prospective follow-up study was carried out over a period of 1 year and included 423 cases. The mean number of cases per month was 35.3 and per day was 1.2. The total number of beds in the PICU of Gharian teaching hospital was 5 , the mean number of cases for each bed per month was 7 and the mean duration of stay was 4.1 days. The characteristics of the studied cases are summarized in Table 1. The proportions of females and males in the sample were similar ( $48.7 \%$ versus $51.3 \%)$. The age range was 1 month to 6 years and the majority were aged $<2$ years $(69.5 \%)$. The underlying cause of admission to the PICU revealed that $28.1 \%$ of cases presented with respiratory diseases, $20.6 \%$ with neurological diseases, $20.1 \%$ with gastrointestinal diseases, $13.9 \%$ with cardiac diseases and $17.3 \%$ with other conditions (diabetic ketoacidosis, renal conditions, organophosphorus poisoning, septicaemia, preoperative preparation, postoperative care, and drug poisoning). The PRISM scores ranged from 1 to 34 with a mean of 14.7. 
Table 1 Characteristics of the study sample of children admitted to the paediatric intensive care unit (PICU) $(n=423)$

\begin{tabular}{|c|c|c|}
\hline Variable & No. & $\%$ \\
\hline \multicolumn{3}{|l|}{ Age (years) } \\
\hline$<2$ & 294 & 69.5 \\
\hline$\geq 2-6$ & 129 & 30.5 \\
\hline \multicolumn{3}{|l|}{ Sex } \\
\hline Male & 217 & 51.3 \\
\hline Female & 206 & 48.7 \\
\hline \multicolumn{3}{|l|}{ Duration of stay (weeks) } \\
\hline$<1$ & 95 & 22.5 \\
\hline$\geq 1$ & 328 & 77.5 \\
\hline \multicolumn{3}{|l|}{ PICU bed occupancy rate } \\
\hline $2 / 5(40 \%)$ & 142 & 33.6 \\
\hline $3 / 5(60 \%)$ & 95 & 22.5 \\
\hline $4 / 5(80 \%)$ & 137 & 32.4 \\
\hline $5 / 5(100 \%)$ & 49 & 11.6 \\
\hline \multicolumn{3}{|c|}{ Cause of admission (underlying diseases) } \\
\hline Respiratory & 119 & 28.1 \\
\hline Neurological & 87 & 20.6 \\
\hline Gastrointestinal tract & 85 & 20.1 \\
\hline Cardiac & 59 & 13.9 \\
\hline Other ${ }^{\mathrm{a}}$ & 73 & 17.3 \\
\hline \multicolumn{3}{|l|}{ PRISM score } \\
\hline $1-9$ & 77 & 18.2 \\
\hline $10-19$ & 168 & 39.7 \\
\hline $20-29$ & 100 & 23.6 \\
\hline$\geq 30$ & 78 & 18.4 \\
\hline \multicolumn{3}{|c|}{ Presence of iatrogenic illness } \\
\hline Yes & 97 & 22.9 \\
\hline No & 326 & 77.1 \\
\hline \multicolumn{3}{|c|}{ Type of iatrogenic complication ${ }^{b}$} \\
\hline \multicolumn{3}{|l|}{ Human error } \\
\hline Yes & 78 & 18.4 \\
\hline No & 345 & 81.6 \\
\hline \multicolumn{3}{|l|}{ Mechanical error } \\
\hline Yes & 19 & 4.5 \\
\hline No & 404 & 95.5 \\
\hline \multicolumn{3}{|l|}{ Outcome } \\
\hline Dead & 32 & 7.6 \\
\hline Alive & 391 & 92.4 \\
\hline
\end{tabular}

${ }^{a}$ Diabetic ketoacidosis, renal conditions, organophosphorus poisoning, septicaemia, preoperative preparation, postoperative care and drug poisoning .

${ }^{b}$ According to Joseph et al. [3].

PRISM = paediatric risk of mortality [6].

\section{latrogenic illness rate}

The rate of iatrogenic illness among the studied cases is presented in Table 2. The occurrence of iatrogenic illness significantly increased with: lower patientage ( $<2$ years), prolonged duration of stay in the PICU ( $\geq 1$ week), presence of respiratory and neurological diseases, high PRISM score $(\geq 30)$ and higher bed occupancy rate in the unit $(>3 / 5)$. The incidence of iatrogenic illness was significantly higher among ventilated cases $(54.5 \%)$ compared with nonventilated ones $(21.2 \%)(\mathrm{RR}=2.57$, 95\% CI: 1.68-3.94, $P<0.001)$. Out of 12 mechanically ventilated cases with iatrogenic illness, 9 developed ventilator-associated pneumonia and 3 developed septicaemia. The rates of developing iatrogenic illness were $34.5 \%$ for cases admitted to the PICU with respiratory disease, $32.9 \%$ for gastrointestinal disease, $16.1 \%$ for neurological disease, $11.7 \%$ for cardiac diseases and $9.6 \%$ for other disorders. Of the 7 cases with other disorders, 5 had drug-induced complications and 2 had septicaemia. Iatrogenic druginduced complications were detected in 5 cases (1.2\% of admitted cases); 2 cases were due to metoclopramide toxicity, 2 to carbamazepin toxicity and 1 to haloperidol toxicity.

Table 3 displays the distribution of cases with iatrogenic illness according to severity of iatrogenic complications and age, bed occupancy rate and duration of stay. Most cases with moderate and major complications were infants $<2$ years of age ( $92.1 \%$ and $88.9 \%$ respectively, $P<$ 0.01 ), patients admitted when the PICU bed occupancy rate was $>3 / 5(68.4 \%$ and $81.5 \%$ respectively, $P<0.01)$ and patients staying in the PICU $\geq 1$ week ( $81.9 \%$ and $74.1 \%$ respectively, $P<0.05$ ).

\section{Mortality rate}

Out of 423 cases admitted to this PICU over the 1 -year period of this study 32 died, an overall mortality rate of $7.6 \%$. Themortality rate significantlyincreased with lower age, presence of respiratory disease, prolonged stay in the PICU, higher PICU bed occupancy rate and higher PRISM score (Table 4). The mortality rate was higher among cases with iatrogenic complications (13.4\%) than those without $(5.8 \%)(\mathrm{RR}=2.29$, 95\% CI: $1.17-4.48, P<0.05)$. More deleterious outcome was observed with 


\begin{tabular}{|c|c|c|c|c|c|c|c|c|}
\hline \multirow[t]{3}{*}{ Variable } & \multirow{3}{*}{$\begin{array}{c}\begin{array}{c}\text { Total } \\
(n=423)\end{array} \\
\text { No. }\end{array}$} & \multicolumn{4}{|c|}{ Iatrogenic illness } & \multirow[t]{3}{*}{$\mathrm{RR}(95 \% \mathrm{Cl})$} & \multirow[t]{3}{*}{$\chi^{2}$-value } & \multirow[t]{3}{*}{$P$-value } \\
\hline & & \multicolumn{2}{|c|}{ Yes $(n=97)$} & \multicolumn{2}{|c|}{ No $(n=326)$} & & & \\
\hline & & No. & $\%$ & No. & $\%$ & & & \\
\hline Age (years) & & & & & & & 11.64 & $<0.001$ \\
\hline$<2$ & 294 & 81 & 27.6 & 213 & 72.5 & & & \\
\hline$\geq 2-6$ & 129 & 16 & 12.4 & 113 & 87.6 & $2.22(1.35-3.64)$ & & \\
\hline Sex & & & & & & & 0.08 & $>0.05$ \\
\hline Male & 217 & 51 & 23.5 & 166 & 76.5 & & & \\
\hline Female & 206 & 46 & 22.3 & 160 & 77.7 & $1.05(0.70-1.49)$ & & \\
\hline Underlying diseases & & & & & & & 27.5 & $<0.001$ \\
\hline Respiratory & 119 & 41 & 34.5 & 78 & 65.6 & $1.87(1.32-2.63)$ & & \\
\hline Neurological & 87 & 28 & 32.9 & 57 & 67.1 & $1.60(1.11-2.33)$ & & \\
\hline Gastrointestinal tract & 85 & 14 & 16.1 & 73 & 83.9 & $0.65(0.39-1.09)$ & & \\
\hline Cardiac & 59 & 7 & 11.9 & 52 & 88.1 & $0.47(0.23-0.95)$ & & \\
\hline Other & 73 & 7 & 9.6 & 66 & 90.4 & $0.37(0.18-0.77)$ & & \\
\hline Duration of stay (weeks) & & & & & & & 12.56 & $<0.001$ \\
\hline$<1$ & 95 & 9 & 9.5 & 86 & 90.5 & & & \\
\hline$\geq 1$ & 328 & 88 & 26.8 & 240 & 73.2 & $2.83(1.48-5.41)$ & & \\
\hline PICU bed occupancy rate & & & & & & & 20.32 & $<0.001$ \\
\hline$\leq 60 \%$ & 237 & 35 & 14.8 & 202 & 85.2 & & & \\
\hline$>60 \%$ & 186 & 62 & 33.3 & 124 & 66.7 & $2.26(1.56-3.25)$ & & \\
\hline PRISM score & & & & & & & 47.48 & $<0.001$ \\
\hline $1-9$ & 77 & 8 & 10.4 & 69 & 89.6 & $0.40(0.20-0.79)$ & & \\
\hline $10-19$ & 168 & 22 & 13.1 & 146 & 86.9 & $0.45(0.28-0.69)$ & & \\
\hline $20-29$ & 100 & 29 & 29.0 & 71 & 71.0 & $1.37(0.95-1.98)$ & & \\
\hline$\geq 30$ & 78 & 38 & 48.7 & 40 & 51.3 & $2.85(2.05-3.94)$ & & \\
\hline Mechanical ventilation & & & & & & & 13.12 & $<0.001$ \\
\hline Yes & 22 & 12 & 54.5 & 10 & 45.5 & & & \\
\hline No & 401 & 85 & 21.2 & 316 & 78.8 & $2.57(1.68-3.94)$ & & \\
\hline
\end{tabular}

$R R=$ relative risk; $C I=$ confidence interval; $P R I S M=$ paediatric risk of mortality [6].

the use of mechanical ventilation, where the mortality rate was $81.8 \%$ among ventilated cases compared with $3.5 \%$ among non-ventilated ones $(\mathrm{RR}=23.4$, 95\% CI: 13.5-40.7, $P<0.001)$.

\section{Correlations}

Variables that were significantly correlated among studied cases are presented in Table 5. There was a significant correlation between the presence of iatrogenic illness and each of the following variables: PRISM score $(r=0.68)$, use of mechanical ventilation $(r=0.53)$, PICU bed occupancy rate $(r=0.52)$, presence of respiratory disease $(r=0.46)$, duration of stay in the PICU $(r=0.44)$ and age $(r$
$=-0.38)$. Also mortality outcome was significantly correlated to the following variables: PRISM score $(r=0.87)$, use of mechanical ventilation $(r=0.76)$, presence of iatrogenic complications $(r$ $=0.40$ ), severity of iatrogenic complications $(r=0.55)$, presence of respiratory disease $(r=0.37)$, duration of stay in the PICU $(r=0.52)$, bed occupancy rate $(r$ $=0.48)$ and age of the child $(r=-0.41)$.

\section{Discussion}

\section{latrogenic illness}

This study revealed that the incidence of iatrogenic complications among children admitted to the PICU of Gharian teaching hospital was $22.9 \%$. Human errors as a cause of iatrogenic illness was found in $18.4 \%$ of studied cases and machine or equipment defects were the cause in $4.5 \%$. This was in agreement with the results of other studies $[3,4,7]$. Payen et al. reported iatrogenic disease (due to human errors or machine/ equipment defects) in $21.6 \%$ of cases in a PICU [4]. Thierry et al. reported that human errors were responsible for $18.6 \%$ of the cases of iatrogenesis in his study [7]. Joseph et al. reported that human errors were responsible for $4.0 \%$ of the total number of cases admitted to the PICU and machine or equipment 


\begin{tabular}{|c|c|c|c|c|c|c|c|c|c|c|}
\hline \multirow[t]{3}{*}{ Variable } & \multicolumn{8}{|c|}{ Severity of iatrogenic complications } & \multirow[t]{3}{*}{$x^{2}$-value } & \multirow[t]{3}{*}{$P$-value } \\
\hline & \multicolumn{2}{|c|}{$\begin{array}{l}\text { Minor } \\
(n=32)\end{array}$} & \multicolumn{2}{|c|}{$\begin{array}{l}\text { Moderate } \\
\quad(n=38)\end{array}$} & \multicolumn{2}{|c|}{$\begin{array}{c}\text { Major } \\
(n=27)\end{array}$} & \multicolumn{2}{|c|}{$\begin{array}{c}\text { Total } \\
(n=97)\end{array}$} & & \\
\hline & No. & $\%$ & No. & $\%$ & No. & $\%$ & No. & $\%$ & & \\
\hline \multicolumn{11}{|c|}{ Age (years) } \\
\hline$<2$ & 22 & 68.8 & 35 & 92.1 & 24 & 88.9 & 81 & 83.5 & 7.67 & $<0.01$ \\
\hline$\geq 2-6$ & 10 & 31.3 & 3 & 7.9 & 3 & 11.1 & 16 & 16.5 & & \\
\hline \multicolumn{11}{|c|}{ PICU bed occupancy rate } \\
\hline$\leq 60 \%$ & 18 & 56.3 & 12 & 31.6 & 5 & 18.5 & 35 & 36.1 & & \\
\hline$>60 \%$ & 14 & 43.8 & 26 & 68.4 & 22 & 81.5 & 62 & 63.9 & 9.58 & $<0.01$ \\
\hline \multicolumn{11}{|c|}{ Duration of stay (weeks) } \\
\hline$<1$ & 16 & 50.0 & 7 & 18.4 & 7 & 25.9 & 30 & 30.9 & & \\
\hline$\geq 1$ & 16 & 50.0 & 31 & 81.6 & 20 & 74.1 & 67 & 69.1 & 8.54 & $<0.05$ \\
\hline
\end{tabular}

$R R=$ relative risk $C \mathrm{Cl}=$ confidence interval .

defects were the reason for $4.3 \%$ of admitted cases [3] and Marcin et al. reported that machine or equipment defects were responsible for $7.6 \%$ of admitted cases [9].

This study also revealed that the frequency of iatrogenic illness was higher in infants $<2$ years of age (27.6\%) than those aged $\geq 2$ years $(12.4 \%)$ and this association was significant. This has been reported by other studies [10,11]. Libby et al. reported that the rate of iatrogenic illness in young children ranged from $25 \%-29 \%$ and that the rate increased at lower ages [10].

In the present study, the proportions of females and males in the sample were similar (48.7\% versus $51.3 \%)$ and there were no sex differences in the occurrence of iatrogenic illness: $22.3 \%$ of females and $23.5 \%$ of males. This was in accordance with other studies $[12,13]$.

The mean duration of stay in the PICU in this study was nearly 4 days and the frequency of iatrogenic illness increased as the duration of stay increased: $26.8 \%$ among patients staying in the PICU $\geq 1$ week compared with 9.5\% among those staying $<1$ week. This agrees with other evidence that the risk of iatrogenic illness increased when the duration of stay was longer than 1 week $[9,14]$.
The distribution of cases according to the cause of admission to the PICU revealed that the most common reason was respiratory disease, followed by neurological, gastrointestinal tract, cardiac and other diseases. The risk of developing iatrogenic illness was also highest for cases admitted with respiratory disease: $34.5 \%$ of cases of iatrogenic illness had respiratory disease compared with $28.1 \%$ of all cases admitted to the unit. These findings were in agreement with reports from numerous studies [15-18]. However, in 4 PICUs in Moscow, the most common cause of admission in was neurological disorders [17] and Marcin et al. also reported that most of the complications developed in cardiac cases and only $3.5 \%$ of cases with GIT disorders had iatrogenic complications [9]. Iatrogenic drug-induced complications were recorded in $5(1.2 \%)$ admitted cases. This agrees with Ross et al [1] who reported that drug-induced complications accounted for $2.1 \%$ of cases admitted to a PICU, whereas Payen et al. reported that iatrogenic medications errors represented as much as $14.7 \%$ of admitted cases [4].

A significant positive correlation was found between the occurrence of iatrogenic illness and the use of mechanical ventilation: the incidence of iatrogenic illness was $54.5 \%$ among ventilated cases compared with only $21.2 \%$ of non-ventilated cases. Out of 12 mechanically-ventilated cases with iatrogenic illness, 9 (75.0\%) developed ventilator-associated pneumonia and 3 cases developed septicaemia. Others have reported that pneumonia is a frequent iatrogenic complication of mechanical ventilation, with an incidence ranging from $9 \%$ to $80 \%$, depending on the duration of mechanical ventilation and the diagnostic methods employed [9].

The PRISM score measures illness severity, based on abnormalities observed in the bedside examination and laboratory assessments [6]. In the present study, the PRISM score ranged from 1 to 34 with mean of 14.7, which is higher than the study of Wang et al. in which the PRISM score ranged from $0-35$ with mean of 6.48 [19], this could be explained by the fact that Gharian teaching hospital is a referral centre for the whole province and there is no PICU in the general hospitals in the local area. Among our cases, the highest rate of iatrogenic illness (48.7\%) was observed among cases with PRISM score $\geq 30$. Other reports showed that cases with higher PRISM score were more liable to develop complications during their ICU stay [9]. 


\begin{tabular}{|c|c|c|c|c|c|c|c|c|}
\hline \multirow[t]{3}{*}{ Variable } & \multirow{3}{*}{$\begin{array}{c}\text { Total } \\
(n=423)\end{array}$} & \multicolumn{4}{|c|}{ Outcome } & \multirow[t]{3}{*}{ RR $(95 \% \mathrm{CI})$} & \multirow[t]{3}{*}{$\chi^{2}$-value } & \multirow[t]{3}{*}{$P$-value } \\
\hline & & \multicolumn{2}{|c|}{$\begin{array}{c}\text { Dead } \\
(n=32)\end{array}$} & \multicolumn{2}{|c|}{$\begin{array}{c}\text { Alive } \\
(n=391)\end{array}$} & & & \\
\hline & & No. & $\%$ & No. & $\%$ & & & \\
\hline Age (years) & & & & & & & 7.29 & $<0.01$ \\
\hline$<2$ & 294 & 29 & 9.9 & 265 & 90.1 & $4.20(1.30-13.7)$ & & \\
\hline$\geq 2-6$ & 129 & 3 & 2.3 & 126 & 97.7 & & & \\
\hline Sex & & & & & & & 0.046 & $>0.05$ \\
\hline Male & 217 & 17 & 7.8 & 200 & 92.2 & $1.08(0.55-2.09)$ & & \\
\hline Female & 206 & 15 & 7.3 & 191 & 92.7 & & & \\
\hline Underlying disease & & & & & & & 11.59 & $<0.05$ \\
\hline Respiratory & 119 & 17 & 14.3 & 102 & 85.7 & $2.89(1.49-5.60)$ & & \\
\hline Neurological & 87 & 4 & 4.6 & 83 & 95.4 & $0.55(0.19-1.53)$ & & \\
\hline Gastrointestinal tract & 85 & 6 & 7.1 & 79 & 92.9 & $0.92(0.39-2.15)$ & & \\
\hline Cardiac & 59 & 2 & 3.4 & 57 & 96.6 & $0.41(0.10-1.67)$ & & \\
\hline Other & 73 & 3 & 4.1 & 70 & 95.9 & $0.50(0.16-1.58)$ & & \\
\hline Duration of stay (weeks) & & & & & & & 5.22 & \\
\hline$<1$ & 95 & 2 & 2.1 & 93 & 97.9 & & & \\
\hline$\geq 1$ & 328 & 30 & 9.2 & 298 & 90.2 & $4.34(1.06-17.9)$ & & \\
\hline PICU bed occupancy rate & & & & & & & 8.62 & $<0.01$ \\
\hline$\leq 60 \%$ & 237 & 10 & 4.2 & 227 & 95.9 & & & \\
\hline$>60 \%$ & 186 & 22 & 11.8 & 164 & 8.2 & $2.80(1.36-5.77)$ & & \\
\hline PRISM score & & & & & & & 45.16 & $<0.001$ \\
\hline $1-9$ & 77 & 2 & 2.6 & 75 & 97.4 & $0.29(0.07-1.23)$ & & \\
\hline $10-19$ & 168 & 5 & 3.0 & 163 & 97.0 & $0.33(0.13-0.85)$ & & \\
\hline $20-29$ & 100 & 5 & 5.0 & 95 & 95.0 & $0.59(0.24-1.51)$ & & \\
\hline$\geq 30$ & 78 & 20 & 25.6 & 58 & 74.4 & $7.37(3.76-14.4)$ & & \\
\hline Iatrogenic illness & & & & & & & 6.13 & $<0.05$ \\
\hline Yes & 97 & 13 & 13.4 & 84 & 86.6 & $2.29(1.17-4.48)$ & & \\
\hline No & 326 & 19 & 5.8 & 307 & 94.2 & & & \\
\hline Mechanical ventilation & & & & & & & 182.9 & $<0.001$ \\
\hline Ventilated & 22 & 18 & 81.8 & 4 & 18.2 & & & \\
\hline Non-ventilated & 401 & 14 & 3.5 & 387 & 96.5 & $23.4(13.5-40.7)$ & & \\
\hline
\end{tabular}

$R R=$ relative risk; $C I=$ confidence interval; $P R I S M=$ paediatric risk of mortality [6].

Our study also revealed that most of the moderate complications (requiring only routine therapy) and major complications (requiring specific intensive care therapy to treat the complication, e.g. artificial ventilation) were observed among infants $<2$ years old $(92.1 \%$ and $88.9 \%$ respectively), those admitted when the PICU bed occupancy rate was $>3 / 5$ (68.4\% and $88.9 \%$ respectively) and patients staying in the PICU $\geq 1$ week $(81.9 \%$ and $69.1 \%$ respectively). These findings agree with many authors $[4,11,12,20]$.

\section{Mortality}

The overall mortality rate of cases admitted to the PICU over the 1-year period of this study was $7.6 \%$. In another study of 9 PICUs the mortality rate ranged from $82.4 \%$ to $97.0 \%$ [21]. The low mortality rate in our study could be because we did not include patients with low Glasgow coma scores at admission. The rate of mortality among cases developing iatrogenic illness was significantly higher than among non-iatrogenic cases
(13.4\% versus $5.8 \%)$. This agrees with the findings of Joseph et al. in which the mortality rate among iatrogenic cases was $15.7 \%$ and among the noniatrogenic cases was $2.7 \%$ [3]. But in another study by the same author the mortality rate among iatrogenic cases was only $4.0 \%$ and among the noniatrogenic cases was $8.9 \%[21]$. El Nawawy reported that the mortality rate among iatrogenic cases was $50.0 \%$ and among non-iatrogenic cases was $38.6 \%$ [11]. Meanwhile, Payen et al. reported 


\begin{tabular}{|c|c|c|}
\hline \multicolumn{3}{|c|}{$\begin{array}{l}\text { Table } 5 \text { Variables significantly correlated with iatrogenic illness and mortality } \\
\text { among children admitted to the paediatric intensive care unit (PICU) }\end{array}$} \\
\hline Variable & $\begin{array}{l}\text { Correlation } \\
\text { coefficient } r\end{array}$ & $P$-value \\
\hline \multicolumn{3}{|l|}{ Presence of iatrogenic illness } \\
\hline PRISM score & 0.68 & $<0.001$ \\
\hline Use of mechanical ventilation & 0.53 & $<0.001$ \\
\hline PICU bed occupancy rate & 0.52 & $<0.001$ \\
\hline Presence of respiratory disease & 0.46 & $<0.001$ \\
\hline Duration of stay in PICU & 0.44 & $<0.01$ \\
\hline Age & -0.38 & $<0.01$ \\
\hline \multicolumn{3}{|l|}{ Mortality outcome } \\
\hline PRISM score & 0.87 & $<0.001$ \\
\hline Use of mechanical ventilation & 0.76 & $<0.001$ \\
\hline Presence of iatrogenic complications & 0.40 & $<0.01$ \\
\hline Severity of iatrogenic complications & 0.55 & $<0.001$ \\
\hline Presence of respiratory disease & 0.37 & $<0.01$ \\
\hline Duration of stay in PICU & 0.52 & $<0.001$ \\
\hline PICU bed occupancy rate & 0.48 & $<0.001$ \\
\hline Age & -0.41 & $<0.01$ \\
\hline
\end{tabular}

PRISM = paediatric risk of mortality [6].

no mortality in relation to any iatrogenic illness in a PICU [4]. This variation in mortality rates may be due to the difference in number of cases, ages of patients and the severity of iatrogenic illness in these various studies.

It was also observed in our study that the mortality rate was higher among infants $<2$ years of age (9.9\%), and there was a negative correlation between age and mortality outcome. This was in agreement with Libby et al. who reported that the mortality rate in young children ranged from $9 \%-90 \%$ [10]. Moreover, El Nawawy reported that the mortality rate increased as age decreased.

In our study there was no significant statistical difference between males and females as regards mortality rate [11]. This was in agreement with Magid et al. [13].

It was observed in this study that mortality rate increased as the duration of stay increased: $9.2 \%$ among cases staying $\geq 1$ week compared with $2.1 \%$ among those staying $<1$ week. A significant positive correlation was present between mortality outcome and duration of stay in the PICU. This was in agreement with Hewitt-Taylor who reported that most patients who stayed for 7 days or more died [22].

This study also revealed that the mortality rate significantly increased with increased bed occupancy rate in the PICU. The mortality rate was $4.2 \%$ when the bed occupancy rate was $\leq$ $60 \%$ and $11.8 \%$ when it was $>60 \%$. This was in agreement with Tilford et al. [20] and Sanchez [23]. We believe that when the occupancy rate in the unit is high, the workload on doctors and nurses is higher, which can lead to a greater risk of iatrogenic illness and therefore greater morbidity and mortality.

In this study the mortality rate among children with respiratory disorders was $14.3 \%$ (the highest rate among the diseases) and a significant positive correlation was found between mortality outcome and the presence of respiratory diseases. This agrees with Thomas et al. who reported that respiratory problems were the commonest cause of death in infants admitted to the PICU [18].

The incidence of iatrogenic illness in this study was significantly higher among ventilated cases (54.5\%) compared with non-ventilated ones (21.2\%). A significant positive correlation was present between the occurrence of iatrogenic illness and the use of mechanical ventilation $(r=0.53)$. This is in agreement with a study by Magid et al. who reported that the mortality rate among ventilated patients was $87.5 \%$ [13]. Mechanical ventilation, while frequently life-saving is also associated with numerous iatrogenic complications, some of which are themselves life-threatening, such as ventilatorassociated pneumonia of patients ventilated for longer than 48 hours, pneumothorax, tension pneumothorax, lung collapse, decreased cardiac output and hypotension [24].

This study also revealed that the frequency of mortality increased as the PRISM score increased, from $2.6 \%$ for cases with PRISM score 1-9, 3.0\% for score $10-19$ and $25.6 \%$ for score $\geq 30$. Singhal et al. reported that the mortality rate was $8.2 \%$ for cases with PRISM score 1-9 [25], 24.4\% for score 10-19 and $66.7 \%$ for score $\geq 30$. These results suggest that PRISM score may be used as a predictor for mortality in the PICU [25].

\section{Conclusion and Recommendations}

Iatrogenic complications represent a real problem in this PICU with an incidence rate of $22.9 \%$ among admitted cases. Human error (18.4\%) followed by machine defects (4.5\%) were the most common causes of iatrogenic complications. The mortality rate was $7.6 \%$ and PRISM score was a good predictor of high-risk cases in the PICU. Mortality outcome was significantly correlated with the occurrence and the severity of iatrogenic 
illness. Moreover both mortality and the occurrence of iatrogenic illness were significantly associated with higher PRISM score, the use of mechanical ventilation, increased bed occupancy rate in the unit, the presence of respiratory disease, prolonged duration of stay in PICU and younger age of the child. Increasing the number of beds in PICU, improving the quantity and quality of manpower with continuous supervision and proper training together with the frequent examination and assessment of patients using PRISM score to detect high-risk cases is recommended to minimize iatrogenic complications and to improve outcomes in the PICU.

\section{References}

1. Ross LM, Wallace J, Paton JY. Medication errors in a pediatric teaching hospital in the UK: five years operational experience. Archives of Disease in Childhood, 2000, 83:492-497.

2. Hurwitz B, Sheikh A. Medical fallibility, cultural recognition and representation. Journal of the Royal Societyof Medicine, 2009, 102:181-185.

3. Joseph JS et al. Complications of care in a pediatric intensive care unit: a prospective study. Intensive Care Medicine, 1996, 22:1098-1104.

4. Payen $\mathrm{V}$ et al. Complications of care in a neonatal- pediatric intensive care: first results of a prospective observational survey. Critical Care Medicine, 2005, 9:259-263.

5. CDC NNIS System. National Nosocomial Infections Surveillance (NNIS) system report, data summary from January 1992 to June 2003, issued August 2003. American Journal of Infection Control, 2003, 31:481-498.

6. Gale AP, ed. Handbook of pediatric intensive care, 1st ed. London, WB Saunders, 2002:45-46.

7. Thierry GS et al. latrogenic complications in adult intensive care units: a prospective study. Critical Care Medicine, 1993, 21:89-102.

8. West $\mathrm{C}$ et al. Association of perceived medical errors with resident distress and empathy: a prospective longitudinal study. Journal of the American Medical Association, 2006, 296:1071-1078.

9. Marcin JP et al. Long-stay patients in the pediatric intensive care unit. Critical Care Medicine, 2001, 29(3):652-657.

10. Libby AM et al. Costs of childhood physical abuse. Pediatrics, 2003, 112:58-65.

11. El-Nawawy A. Evaluation of the outcome of patients admitted to the pediatric intensive care unit in Alexandria using the pediatric risk of mortality (PRISM) score. Journal of Tropical Pediatrics, 2003, 49:109-114

12. Ksouri $\mathrm{H}$ et al. latrogenic complications in the ICU: prospective study during17 months Rabta, Tunis, Tunisia. Critical Care, 2006, 10:393.

13. Magid A, Hanan M, Waheeb N. Outcome of Ain Shams pediatric intensive care unit in two years duration [Masters thesis]. Cairo
Egypt, Department of Paediatrics, Faculty of Medicine, Ain Shams University 2001.

14. Briassoulis $\mathrm{G}$ et al. Acute and chronic paediatric intensive care patients: current trends and perspectives on resource utilization. $Q / M, 2004,97: 541$

15. Ay G, Mok Q. Identifying futility in a paediatric critical care setting: a prospective observational study. Archives of Disease in Childhood, 2001, 84: 265-268.

16. Clay AS, Behnia M, Brown KK. Mitochondrial disease: a pulmonary and critical-care medicine perspective. Chest, 2001, 120:634-648.

17. DiCarlo JV et al. Comparative assessment of pediatric intensive care in Moscow, the Russian federation prospective multicenter study. Critical Care Medicine, 1996, 27:1403-1407.

18. David JV, Thomas B, Jerry Z. Acute respiratory distress syndrome. eMedicine, 2003, (4):3.

19. Wang JN et al. Comparison of intensive care of injured children between pediatric-based and non-pediatric-based intensive care units in a university hospital in Taiwan. Acta Paediatrica Taiwanica, 1999, 40:400-405.

20. Tilford JM et al. Volume-outcome relationships in pediatric intensive care units. Pediatrics, 2000, 106:289-294.

21. Joseph JS, Murray MP. Iatrogenic illness in pediatric critical care. Critical Care Medicine, 1996, 18:984-988.

22. Hewitt-Taylor J. Children who require long-term ventilation: staff education and training. Intensive and Critical Care Nursing, 2004, 20:93-102.

23. Chrusch CA et al. High occupancy increases the risk of early death or readmission after transfer from intensive care. Critical Care Medicine, 2009, 37(10):2753-2758.

24. Katz $\mathrm{S}$ et al. Outcome of non-invasive positive pressure ventilation in paediatric neuromuscular disease. Archives of Disease in Childhood, 2004, 89:1214.

25. Singhal DN et al. Prediction of mortality by application of PRISM score in intensive care unit. Indian Pediatrics, 2001, 38:714-719. 